\title{
Los bancos y la responsabilidad social como medición del éxito
}

\author{
ANTONIO DE LA HAZA BARRANTES*
}

Cada uno de nosotros debe hacer lo correcto... incluso cuando hacer lo correcto parezca entrar en conflicto con el logro de objetivos de ventas o utilidades.

Rick Waugh

\begin{abstract}
SUMARIO: I. PARA UNA EMPRESA BANCARIA, ¿CÓMO SE LOGRA QUE LA RESPONSABILIDAD SOCIAL SE TORNE UNA HERRAMIENTA DE MEDICIÓN DE ÉXITO?- II. ¿CON QUÉ HERRAMIENTAS CUENTAN LAS EMPRESAS BANCARIAS PARA LLEVAR ADELANTE SUS POLÍTICAS DE RS?- III. DE LA PALABRA A LOS HECHOS EN EL PERÚ DE HOY.- VI. A MANERA DE CONCLUSIÓN.
\end{abstract}

Cada día con mayor frecuencia nos estamos acostumbrando a titulares en los medios de comunicación que, por ejemplo, señalen:

El banco tal fue reconocido por dar a conocer la divulgación de la producción del carbono a nivel regional o se negó a abrir una cuenta de ahorros a favor de fulanito de tal, porque al aplicar la «política de conocimiento del cliente» se percató de que no acreditó de forma satisfactoria el origen de su dinero por estar presumiblemente vinculado a un delito precedente por lavado de activos ${ }^{1}$. Ambos casos son indiscutiblemente responsabilidad social.

Las empresas ${ }^{2}$ bancarias a nivel mundial constituyen seguramente uno de los sectores más regulados. Su justificación, en muchos casos, es de orden legal y económico: está fundada en que los bancos administran el ahorro del público y en que son vías que llevan adelante la política

* Es abogado por la Pontificia Universidad Católica del Perú y magíster en Derecho Empresarial por la Universidad de Lima, con estudios doctorales concluidos en la PUCP, donde también es profesor de Derecho Bancario.

1 «Se entiende por lavado de dinero o de activos, aquella actividad o conjunto de actividades que buscan introducir bienes en general proveniente de actividades ilícitas dentro del circuito económico financiero nacional buscando ocultar el origen de su fuente ilícita, existiendo una asociación entre bien y delito; el objetivo de la legislación es destruir esta asociación [...] ya no es solamente narcotráfico o terrorismo, sino que la ley responde a la necesidad de sancionar delitos conexos a los dos mencionados, como son: delitos contra la administración pública, secuestro, proxenetismo, tráfico de menores, defraudación tributaria y delito aduanero. Con ello el legislador ha querido destacar que el delito de lavado de activos es un delito autónomo». En DE LA HAZA BARRANTES, Antonio. «No se lo digas a nadie pero él es un PEPs...». En El Derecho frente a la ciencia y la tecnología. Libro homenaje a César Delgado Barreto y César Fernández Arce. Lima: PUCP, 2007, p. 271.

2 «Comprendemos por empresa [...] la organización económica dedicada a la producción o comercialización de bienes o a la prestación de servicios, con sus elementos esenciales». En Beaumont CalliRgos, Ricardo. Comentarios a la Nueva Ley General de Sociedades. Lima: Gaceta Jurídica, 1988, p. 629. 
monetaria, por lo que para operar deben contar con una licencia de la autoridad pública ${ }^{3}$.

En nuestro país, los bancos, al igual que una empresa financiera, una caja municipal de ahorro y crédito, de crédito popular, rural, una EDPYME o una cooperativa de ahorro y crédito; son empresas de operaciones múltiples, conocidas también como banca universal, mixta o multibanca. Ello responde al criterio de la unificación de los servicios financieros con la finalidad de que se otorguen al cliente a través de una sola entidad. Puede ser entendida como la empresa que posibilita no solo el recurso pecuniario sino también el técnico, es decir, que actúa tanto durante la producción como durante la comercialización y el consumo ${ }^{4}$. Los estándares emanados de estas empresas de operaciones múltiples comprenden criterios diversos: capital mínimo, principios en materia de negocios y seguros, lavado de activos, gobierno corporativo, protección al consumidor financiero, principios contables y de auditoria, normas de control, supervisión y conglomerado financiero, entre otros.

A pesar de todos los controles normativos, nadie puede dudar que hoy nos enfrentamos a una crisis financiera internacional, originada en los países desarrollados, que se expande por todos los continentes y que tiende a jaquear el sistema financiero nacional y nuestro crecimiento económico. No por ello, sin embargo, se debe alterar el compromiso de la responsabilidad social (RS), porque en nuestro país ha generado que gran parte de la población tenga la expectativa de que la empresa privada sea un mecanismo para la satisfacción de sus necesidades básicas, por la articulación que existe entre ella y la sociedad civil. Por el lado de juristas y empresarios, la RS ha empezado a captar mayor atención. Fue el tema tratado durante el CADE 2009, en la ciudad de Arequipa, y a raíz de ello se han iniciado actividades para promover las prácticas de RS.

Nosotros, podemos definirla como una nueva forma de hacer negocios. En esta, la empresa gestiona sus operaciones en armonía con lo económico, lo social y lo ambiental, y reconoce los intereses del público con el que se relaciona: accionistas, empleados, comunidad, proveedores y clientes $^{5}$. La definición nos permite verificar que no tiene nada de novedoso. Comprende aspectos que no necesariamente son normas jurídicas y que constituyen prácticas internas de una empresa. $\mathrm{O}$ se trata, en todo caso, de temas de interés, como políticas crediticias, o de la inversión de toda institución financiera con relación a la sociedad civil donde se ubica. Es una actitud basada en un conjunto de reglas internas de la organización. Esta determina la forma en que las empresas modernas se conducen y administran, y se vincula a lo que debemos entender hoy

3 El Estado fomenta y garantiza el ahorro. La ley establece las obligaciones y los límites de las empresas que reciben ahorros del público, así como el modo y los alcances de dicha garantías. Artículo 87 de la Constitución Política del Estado, 1993.

4 En DE LA HAZA BARRANTES, Antonio. Derecho bancario y las cajas municipales en la banca múltiple. Lima: Universidad de Lima, 2002, p.25.

5 En «Forum Empresa». Diario Gestión, 26 de enero de 2010, p. 25. 
por gobierno corporativo. De hecho, el gobierno de las empresas es, a fin de cuentas, el objeto del Derecho de sociedades: la organización y el funcionamiento de las sociedades, las relaciones entre sus socios, entre estos y los administradores, y las relaciones de la sociedad con sus acreedores y otros terceros interesados 6 .

El presente artículo busca, de manera ágil y funcional, responder algunas inquietudes básicas que motivan la RS de una empresa bancaria.

\section{PARA UNA EMPRESA BANCARIA, ¿CÓMO SE LOGRA QUE LA RESPONSABILIDAD SOCIAL SE TORNE UNA HERRAMIENTA DE MEDICIÓN DE ÉXITO?}

Un banco es aquella institución cuyo negocio principal consiste en recibir dinero del público — como depósito o bajo cualquier otra modalidad contractual - para utilizarlo, junto con su propio capital y el que obtenga de otras fuentes de financiación, en conceder créditos mediante diversas modalidades o en aplicarlos a operaciones sujetas a riesgos de mercado?

Sin embargo, para que la RS sea viable, el «éxito» debe ser visto no solo en términos de criterios financieros, sino que debe estar basado en una relación entre la empresa y la sociedad civil: la empresa representada por los empleados de la organización; la sociedad civil, por la satisfacción y por los intereses de los clientes de la empresa ante el apoyo que esta brinda a la comunidad donde opera.

Toda organización empresarial, en general, realiza un balance de su gestión. Hoy dentro de dicho balance debe incluir su RS, que a la vez debe influir en el ambiente de las inversiones como una buena práctica.

Evidentemente, la RS de la empresa debe encajar con sus objetivos económicos. Una estrategia de negocio debe ser sostenible en el largo plazo. Una empresa será rentable en la medida en que el negocio en sí mismo lo sea, para lo cual dependerá de la convicción de los funcionarios de dirección que la lideran. Pero esto no debe entenderse solamente como una inversión que debe generar un retorno, sino como un vínculo con la comunidad dentro de una filosofía empresarial ${ }^{8}$.

6 PAYET, José Antonio. «Empresa, gobierno corporativo y Derecho de sociedades: reflexiones sobre la protección de las minorías». Themis, № 46, p. 78, 2003, Lima.

7 Numeral 1 , artículo $282^{\circ}$, de la Ley 26702. El sistema financiero nacional está conformado por quince bancos. Trece de ellos cuenta con un accionista extranjero como socio principal. Entre estos podemos mencionar el Banco Continental, el Banco de Comercio, el Banco de Crédito del Perú, el Banco Financiero, el Banco Interamericano de Finanzas, Scotiabank Perú, Citibank, Interbank, Mibanco, HSBC Bank Perú, el Banco Falabella, el Banco Santander Perú, el Banco Ripley, el Banco Azteca Perú y Deustsche Bank Perú.

8 Mario Coronado, director de la Fundación Telefónica, señala que no es fácil asumir una posición auténticamente comprometida con la responsabilidad social empresarial y mantener la sostenibilidad del negocio. Su empresa realizó un incremento presupuestario para continuar con la inclusión social a través de las TIC. Asimismo, en el Programa Proniño aumentó el número de participantes de 17 mil a 30 mil en un contexto de crisis. En «Muy bien después de todo». Semana económica, № 1206, p. 34,2010 , Lima.

LOS BANCOS Y LA RESPONSABILIDAD SOCIAL COMO MEDICIÓN DEL ÉXITO 
Es necesario, primero, que los empleados se sientan orgullosos y se identifiquen con la RS de su empresa, que esta se vuelva una «firma distintiva» de la organización. Al comprender que es buena en sí misma, se convierte en una necesidad. Asimismo, constituye una oportunidad de negocio, pues se establece una relación duradera con el cliente, que va desde el aumento de las actividades de microfinanciamiento hasta programas que promueven, por ejemplo, la incorporación de la mujer dentro de la vida laboral, pasando por aquellos vinculados con protección y cuidado del medio ambiente — como tema central de nuestra época-.

La RS también debe ser vinculada a las políticas de buen gobierno corporativo. No tiene que ver únicamente con conceptos de transparencia, sino con dirección, gestión y cumplimiento de objetivos medibles de la organización. El gobierno interno, que al final son las personas que conforman el directorio o los niveles gerenciales de primera y segunda línea, es responsable de estructurar la cultura organizacional mediante las pautas para la conducta en los negocios. Ello representa un elemento de la integridad y de las prácticas éticas sobre cómo se vende un producto financiero, e incluye aspectos que van desde brindar protección a la intimidad del cliente mediante la aplicación correcta de la reserva bancaria, hasta el trato al mismo empleado de la organización o al proveedor de productos con equidad.

También puede tratarse de pautas para enfrentar temas que pueden afectar una empresa bancaria, como actos de financiamiento del terrorismo, riesgos legales - denuncias por negocios financieros fraudulentos, por ejemplo- o gestión del riesgo, mediante controles adecuados para ejecutar actividades con eficacia: los normativos y los de reputación. Aunque estas pautas abarquen una amplia serie de temas, no siempre es factible que cubran todas las situaciones que podrían presentarse. Por ello, es necesario que exista comunicación en el interior de la organización, entre todos los niveles gerenciales, sobre cualquier posible problema que se presente.

En nuestro medio, ciertas empresas bancarias de primera línea han normado lo que denominan «negocios restringidos o de alto riesgo», es decir, actividades ilegales o cuya legalidad es tan cuestionable que ponen en riesgo la imagen o el buen nombre del mismo banco o de alguna empresa que forma parte del grupo económico. Entre estos negocios restringidos podemos mencionar los siguientes:

- servicios financieros no reglamentados;

- actividades o ventas cuestionables;

- juegos de azar, pornografía y servicios relacionados con el sexo;

- casinos autorizados;

- agencias de viajes;

- comercio de joyas, gemas y piedras preciosas; 
- presencia de personas políticamente expuestas;

- presencia de personas naturales o jurídicas a quienes hubiere levantado el secreto bancario;

- clientes radicados en paraísos fiscales; y

- operadores de cajeros automáticos privados.

SUS POLIITICAS DE RS?

Indiscutiblemente, la principal herramienta es el capital humano. Adicionalmente, para lograr su cometido las empresas aplican lo que se tiende a denominar el «cuadro de mando integral» — también conocido como balanced scorecard o BSC-, que toma en consideración el bienestar de todas las partes interesadas, a saber, accionistas, empleados y clientes. Comienza por medir el desempeño de empleados y equipo ejecutivo en cuatro áreas claves: finanzas, operaciones, clientes y empleados.

Un BSC se basa en la experiencia ganada como empresa enfocada en:

- mejorar los plazos para definir esquemas, objetivos, indicadores y metas;

- implementar un procedimiento mensual de evaluación, seguimiento y gestión por unidades de la empresa; y

- alinear los formatos de revisión de desempeño del personal, reconocimientos e incentivos con el BSC.

Una vez logrados estos tres puntos, los pasos siguientes son:

\section{I.1. Definiciones}

Se relaciona con los objetivos corporativos de la empresa y con los documentos elaborados durante los procesos del plan estratégico, de negocios y de rentabilidad. Para el plan estratégico, se realizan las siguientes tareas:

- revisión y actualización del esquema de objetivos estratégicos de las unidades —no solamente las unidades de negocios-;

- actualización de los indicadores a ser medidos;

- fijación de las metas de los indicadores — con relación al plan de rentabilidad-.

\section{II.2. Revisión de desempeño del personal}

Sobre la base del BSC de la unidad, los miembros de las respectivas áreas, en coordinación con sus jefaturas, definirán en cascada sus formatos de revisión de desempeño. 


\section{3. Seguimiento mensual de los BSC de la unidad}

- Se identificarán las áreas proveedoras de los datos para la elaboración de indicadores.

- Se conducirán las mediciones de avance (real frente a meta).

Por otro lado, para elaborar el BSC, debe considerarse el plan de negocios que detalla las características propias de la gerencia de primera línea que administra: visión, misión, fortalezas, oportunidades, debilidades y amenazas — sea esta de negocio, soporte o staff—, su razón de ser, su situación actual, sus objetivos estratégicos — expresados en el formato BSC definido por la gerencia general-, sus metas para el año - las cuales deben ser consistentes con la información contenida en el plan de rentabilidad — y los planes de acción que llevará a cabo para alcanzar dichos objetivos, metas y factores críticos de riesgo.

A continuación, se presenta un gráfico que permite ilustrar lo afirmado:

Objetivos para obtener una certificación en equidad de género.

Perspectiva Financiera

Perspectiva del Cliente
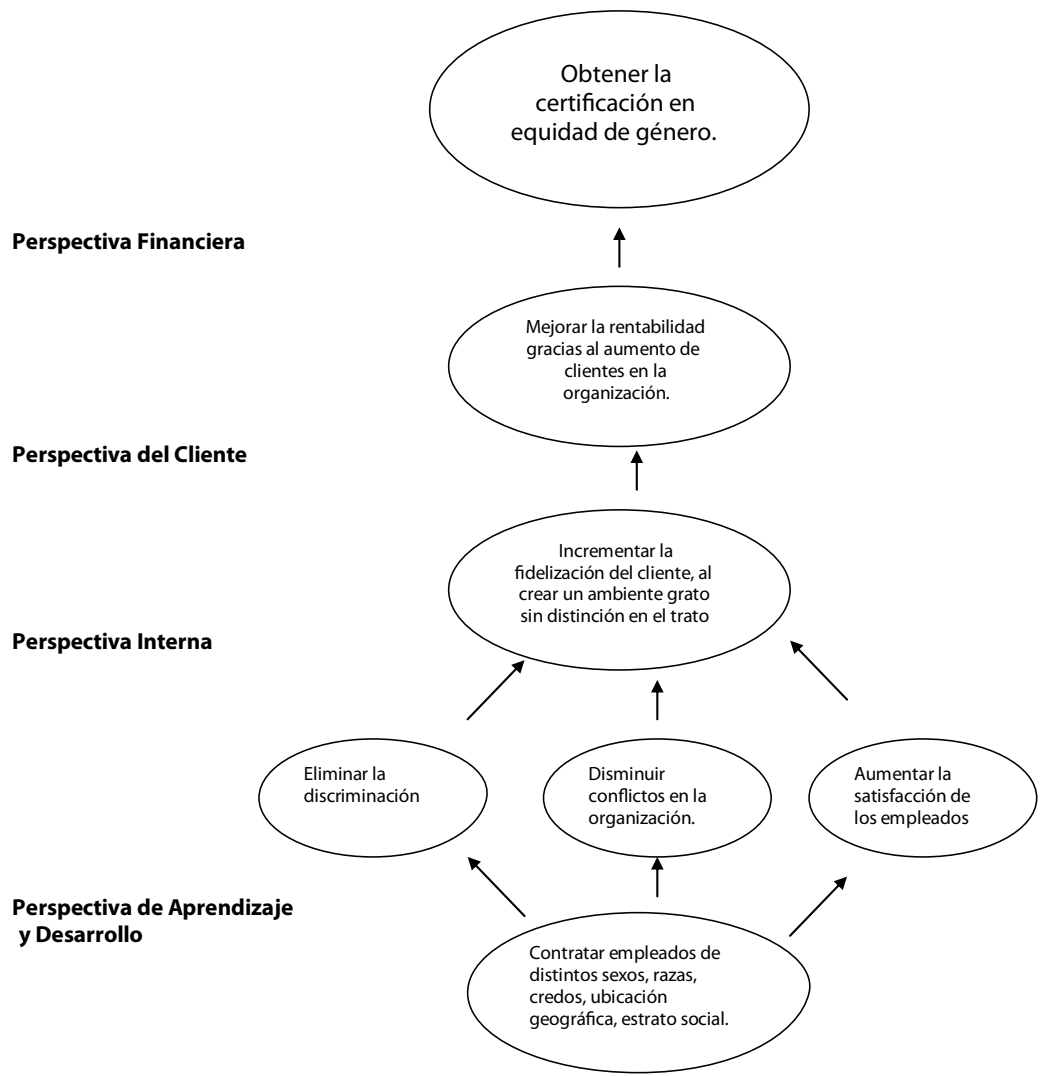
Otro mecanismo, que debe ser considerado como herramienta de medición del éxito para una empresa bancaria en el tema de la RS, es el aprovechamiento del conocimiento y la experiencia financiera para elevar el nivel de bancarización de nuestro país mediante mecanismos de inclusión social.

Para la sociedad civil, representada en el cliente de la empresa como consumidor de productos bancarios - cuentas de ahorros, tarjetas de crédito o acceso a créditos hipotecarios-, la RS debe constituir el interés en conocer cómo está elaborado o fabricado el producto. El cliente tiene la posibilidad de castigar o de premiar al empresario que asume estándares mínimos o máximos que deben observarse para saber adónde van los ingresos de las empresas, por ejemplo:

- ingresos repartidos entre accionistas, empleados y Estado;

- ingresos repartidos entre empleados por medio de sueldos;

- ingresos repartidos al Estado a través del pago de impuestos;

- ingresos repartidos entre accionistas mediante la distribución de dividendos; e

- ingresos repartidos a la misma empresa mediante una reinversión de utilidades.

Para las empresas, la RS también debe vincularse con la educación, entendida como formación empresarial, no solo teórica sino también práctica. En esta, no debe distinguirse entre edades ni roles, y debe informase sobre el sistema financiero en general. El Banco de Crédito del Perú (BCP), por ejemplo, cuenta con un programa vinculado con educación: el ABC de la Banca, desarrollado desde $2007^{9}$.

\section{DE LA PALABRA A LOS HECHOS EN EL PERÚ DE HOY}

La RS para una empresa se inicia por intermedio de programas pilotos. Entre ellos, podemos mencionar en nuestro medio el Eco Scotiabank (Scotiabank), un programa interno que aspira a que el banco sea una empresa eco-eficiente. Por ahora, se trata de una campaña piloto de comunicación para sensibilizar a los colaboradores sobre cuán importante son el reciclaje y la disminución del consumo de luz, agua y papel para el cuidado del medio ambiente. Se realiza en colaboración con Ciudad Saludable, una ONG que trata de formalizar a los recicladores al asociarlos para que comercialicen los residuos clasificados por el banco. Esta iniciativa genera un incremento de los ingresos en las familias que participan de ella, además de disminuir los impactos negativos en el medio ambiente. Asimismo, Scotiabank ofrece a los recicladores préstamos

LOS BANCOS Y LA RESPONSABILIDAD SOCIAL COMO MEDICIÓN DEL ÉXITO 
para que puedan comprar equipos $\mathrm{u}$ otros elementos necesarios para realizar mejor su trabajo ${ }^{10}$.

En esta misma línea, el BCP viene desarrollando un programa piloto de microcréditos dirigido a madres de familia en Ventanilla. Este impartirá capacitación en gestión empresarial con el fin de acceder al crédito por primera vez y se desarrollará bajo el modelo de banca comunal. El BCP está trabajando con SNV de Holanda, entidad que diseñó el proyecto ${ }^{11}$.

El Grupo BBVA Banco Continental ha lanzado el programa Caja Nuestra Gente y Cajeros Corresponsales, mediante el cual se llegan a cubrir plazas a las que el banco mismo no llega. Con un presupuesto inicial de 20 millones de euros por parte de la Fundación del Grupo de Microfinanzas destinado a las operaciones de Perú, Colombia y México, la caja cuenta con una participación del 39,26\% del mercado peruano de cajas rurales de ahorro y crédito, con un total de S/. 530784 millones de colocaciones a noviembre del año pasado. Hacia septiembre de 2009, sus cajeros corresponsales sumaron 546 a nivel nacional. El presupuesto designado para ellos es el del 0,7\% de las utilidades después de impuestos generados por el banco ${ }^{12}$.

\section{A MANERA DE CONCLUSIÓN}

De todas estas experiencias sobre responsabilidad social empresarial podemos arribar a dos conclusiones esenciales:

1. Ser socialmente responsable se convierte en una necesidad para la empresa bancaria y debe estar considerado dentro de su plan de negocios.

2. Es necesario que la sociedad civil, representada en el cliente, se convenza de que tiene la posibilidad de premiar o de castigar a una empresa cuando observa que se aparta de los estándares mínimos de lo que se considera una buena práctica organizativa en lo que respecta a ser responsable socialmente. El castigo consistiría simplemente en no consumir el producto que se le ofrece.

10 En «Prevenir y mitigar para combatir el friaje». Suplemento de la revista Cosas, № 10, p. 38, 2009, 